\title{
Phytochemical and GC-MS Analysis of Hydro Ethanolic Leaf Extract of Ocimum sanctum (L.)
}

\author{
Atul Srivastava ${ }^{1}$, Subhashini ${ }^{2}$, Anand Kumar Keshari ${ }^{3}$, Ragini Srivastava ${ }^{1, *}$
}

\section{Atul Srivastava ${ }^{1}$, Subhashini², Anand Kumar Keshari', Ragini Srivastava ${ }^{1, *}$}

${ }^{1}$ Department of Biochemistry, Institute of Medical Sciences, Banaras Hindu University, Varanasi, Uttar Pradesh, INDIA.

${ }^{2}$ Department of Zoology, MMV, Banaras Hindu University, Varanasi, Uttar Pradesh, INDIA.

\section{Correspondence}

\section{Dr. Ragini Srivastava}

Professor, Department of Biochemistry, Institute of Medical Sciences, Banaras Hindu University, Varanasi -221005, Uttar Pradesh, INDIA.

Phone no: +91-9935174104

Email id: ragsriv@gmail.com

\section{History}

- Submission Date: 03-05-2021;

- Review completed: 22-06-2021;

- Accepted Date: 24-07-2021

\section{DOI : 10.5530/pres.13.4.16}

Article Available online

http://www.phcogres.com

\section{Copyright}

(C) 2021 Phcog.Net. This is an openaccess article distributed under the terms of the Creative Commons Attribution 4.0 International license.

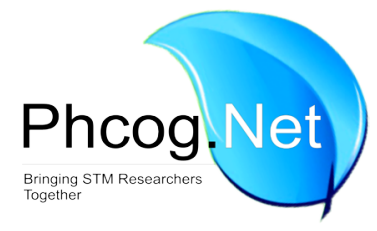

\begin{abstract}
Background: The pharmacological efficiency of herbal drugs has shown to be effective as conventional pharmaceutical drugs. Preliminary screening of herbal extracts helps in analysing the bioactive compounds present. Ocimum sanctum, the queen of herbs keeps a spiritual importance in Indian culture and have important place in traditional medicinal system of India. Objectives: The present study was implement to investigate the preliminary phytochemical screening and GC-MS analysis of leaf extract of $O$. sanctum to determine the phytoconstituents. Materials and Methods: Leaves collected were dried, crushed and mixed with ethanol and water and further applied for extract preparation. The prepare extract was used for phytochemical and GC-MS analysis. Results: In qualitative phytochemical analysis tannins, carbohydrate, quinine, anthraquinones, coumarins, phlobatanins, alkaloids, flavonoids, glycosides, terpenoids, diterpenes, phenols were found present while GC-MS analysis showed Eugenol, Cyclohexane, bicyclo[7.2.0]undec-4-ene, 4,11,11-trimethyl-8-methylene, Oxatricyclo[8.2.0.0(4,6)]dodecane,,12-trimethyl-9-methylene, Tetracontane, Phytol were present in majority. Conclusion: The study concluded that $O$. sanctum leaf extracts contain many biological active compounds which could be exploited for a development of plant based drug. Key words: Phenolics, Flavonoids, Herbal drugs, Phytochemical, GC-MS analysis.
\end{abstract}

\section{INTRODUCTION}

Plants are potent and powerful biochemist with number of phytochemicals incorporated that prevents and treat several disorders. ${ }^{[1]}$ Traditional medicinal practitioners have been using medicinal plants and their parts as stem, leaves, bark, roots, seeds etc since long back to cure various ailments. Phytochemicals present in the plants having therapeutic benefits are considered to be "active ingredients" or "active component" of herbal medicines and provide the primary source for drug development. ${ }^{[2]}$ India, with rich flora has been called as the botanical garden of the world and is the largest producer of medicinal herbs. Medicinal herbs with active ingredients have been found to be powerful source as therapeutics ingredient. Hence, medicinal plants are being of great interest to the researchers in the field of biotechnology, as most of the pharmaceutical compounds are produced from the medicinal plants.

Ocimum sanctum commonly called as "holy basil", "the Queen of herbs" and "Tulsi" is one of the holiest and most exquisite medicinal herbs of India. ${ }^{[3]}$ In India Tulsi, is renowned for its religious and spiritual sanctity, as well as for its important role as a natural and traditional herb for holistic health and herbal medicine. ${ }^{[4]}$ It is also regarded as "elixir of life" in Ayurvedic science due to its potentiality to promote longevity. Ocimum has a unique characteristic pharmacological feature and have been known to have ethno-medicinal property. ${ }^{[5]}$ In the present pandemic COVID-19 scenario, Ocimum has been explored as a component in brew to act as an immunobooster. In the present study the phytochemical screening and GC-MS analysis of O. sanctum has been performed to explore its phyto constituents.

\section{MATERIALS AND METHODS}

\section{Plant material and its collection}

Young and fresh leaves of Ocimum sanctum (L.) for the experiment were collected from Botanical Garden of Banaras Hindu University, Varanasi. The specimen was identified and verified, by Department of Botany, Banaras Hindu University and a voucher number (Lamia.2019/1) was provided.

\section{Preparation of crude extract}

Extract was prepared by the established protocol of Keshari et al. 2017 with certain modification. ${ }^{[6]}$ Fresh and healthy young leaves collected from the Botanical Garden were washed under running water and further with deionised water and then dried in shade and then at $37^{\circ} \mathrm{C}$ in incubator. Dried leaves were further crushed with the help of mixer grinder. Alcoholic extract was prepared by Soxhlet apparatus 
using $5 \mathrm{gms}$ of crushed powered leaves in the Erlenmeyer flask containing $100 \mathrm{ml}$ of $70 \%$ ethanol. The mixture was applied to the apparatus for $24 \mathrm{hr}$ at a temperature not exceeding the boiling point of the solvents. This mixture was then heated for $2 \mathrm{hr}$ on magnetic stirrer at $70^{\circ} \mathrm{C}$. The obtained extract was centrifuged at $5000 \mathrm{rpm}$ for $15 \mathrm{~min}$ and the supernatant was further filtered using Whatmann filter paper No. 1. The prepared concentrated extracts were concentrated to dryness at $40^{\circ} \mathrm{C}$ under reduced pressure using a rotatary evaporator, and then dried extracts were stored at $-18^{\circ} \mathrm{C}$ in air-tight screw-capped glass vials for GC-MS analysis.

\section{Preliminary qualitative phytochemical analysis of extract}

The preliminary screening was performed for the phytochemical analysis of the crude extracts to identify the various phytoconstituents using standard procedures as described by Keshari A et al. and Babu N. R. et al. ${ }^{[6,7]}$ Detection of tannins, phlobatanins, saponinsm, alkaloids, flavonoids, quinine, anthraquinones coumarins, sterols, glycosides, terpenoids, diterpenes, triterpenes, phenols, starch, carbohydrates, proteins was performed.

\section{Gas Chromatography-Mass Spectrometry analysis of test extract}

The ethanolic extract of $O$. sanctum was subjected for GC-MS analysis on a GC-MS Shimadzu GC-MSQP2010 Plus system equipped with RTX-5 m.s. capillary column (0.25 mm X $30 \mathrm{~m} \mathrm{X} 0.25 \mathrm{~lm})$. Helium gas (99.999\%) was used as carrier gas with a constant flow rate of $16.3 \mathrm{ml} / \mathrm{min}$. Column flow rate was maintained $1.2 \mathrm{ml} / \mathrm{min}$. Column temperature was started at $50^{\circ} \mathrm{C}$, held for $2 \mathrm{~min}$, ramped to $250^{\circ} \mathrm{C}$ for $6 \mathrm{~min}$ and finally ramped at $280^{\circ} \mathrm{C}$ and held for $22 \mathrm{~min}$. The extract was prepared as discussed above. Before applying for GC-MS analysis the extract was filtered with syringe filter. The sample was injected in a volume of $20 \mu$ l.

\section{Identification of phytocompound of GC-MS}

Interpretation of mass spectrum GC-MS was performed using the database and the spectrum of the unknown components was compared with the spectrum of known components stored in the library. The name, molecular weight, and structure of the components of the test materials were ascertained. Compounds in the extract were identified using WILEY8.LIB and NIST14s.lib MS data library. The average peak area to the total areas was calculated for comparing relative percentage amount of each component.

\section{Total phenolic and flavonoid content}

Total phenolic and flavonoid content was determined by Folin-Ciocalteu and aluminium chloride method where gallic acid and quercitin was used as standard respectively. Total phenolic content of crude extract was determined according to the established protocol of Jan et al. ${ }^{[8]}$ Briefly reaction mixture was prepared by mixing $1 \mathrm{ml}$ of different concentration of test extract $(100-1000 \mu \mathrm{g} / \mathrm{ml})$ with $5 \mathrm{ml}$ of Folin-Ciocalteu reagent (1:10 dilution). The mixture was kept for $5 \mathrm{~min}$ at room temperature and then $4 \mathrm{ml}$ of sodium carbonate $(115 \mu \mathrm{g} / \mathrm{ml})$ was added. After $2 \mathrm{hr}$ the absorbance was measured at $765 \mathrm{~nm}$ by spectrophotometer (Orion Aquamate 8000 UV-VIS Thermo scientific). Calibration curve was prepared by mixing $1 \mathrm{ml}$ Gallic acid at different concentration $(25-400 \mu \mathrm{g} / \mathrm{ml})$. Total phenolic content in O. sanctum was expressed as Gallic acid equivalent (GAE) mg/gms of the dry extract.

Total flavonoid content was measured with the aluminum chloride colorimetric assay. $1 \mathrm{ml}$ of different concentration of extract $(100-1000 \mu \mathrm{g} / \mathrm{ml})$ or $1 \mathrm{ml}$ of standard quercetin solution $(100-1000 \mu \mathrm{g} / \mathrm{ml})$ was taken into test tubes with $4 \mathrm{ml}$ of distilled water. Reaction mixture was prepared by mixing $0.3 \mathrm{ml}$ of $5 \%$ sodium nitrite solution was added into each,
$0.3 \mathrm{ml}$ of $10 \%$ aluminum chloride (after $5 \mathrm{~min}$ ) and $2 \mathrm{ml}$ of $1 \mathrm{M}$ sodium hydroxide. Finally, volume was made up to $10 \mathrm{ml}$ with distilled water and mixed well. After $15 \mathrm{~min}$ absorbance was measured at $510 \mathrm{~nm}$ by spectrophotometer (Orion Aquamate 8000 UV-VIS Thermo scientific spectrophotometer). The calibration curve was plotted using standard quercetin. The data of total flavonoids of $O$. sanctum were expressed as $\mathrm{mg}$ of quercetin equivalents (QE)/ $100 \mathrm{~g}$ of dry extract.

\section{RESULTS AND DISCUSSION}

In the present era medicinal plants are considered as rich sources of ingredients for new modern drugs. Many of the modern medicines are produced and synthesized from medicinal plants. ${ }^{[9]}$ The analysis and extraction of different plant material and their compounds play an important role in the development, modernization, use and quality control of herbal formulations. ${ }^{[9]}$ Pushpangadan and Bradu (1995) have reported more than 150 species of Ocimum. ${ }^{[10]}$ The phytoconstituents in medicinal herbs varies with species and according to the environmental condition they are grown. Till now the essential oil of $O$. sanctum has been only screened and herbal extract of leaves has not been explored for its phytochemical analysis. ${ }^{[11]}$ Hence the present study was undertaken to find out the bioactive compounds present in the ethanolic extract of O. sanctum by using Gas chromatography and Mass spectroscopy.

Various test to identify compounds facilitates their qualitative estimation study. The preliminary phytochemical screening of the leaf extract was mainly performed to recognize and identify the main bioactive phytocompounds. ${ }^{[12]}$ The result showed the presence of biomolecule compounds such as tannin, carbohydrate, phelobatanins, flavonoid, terpenoids, triterpenes, glycosides, alkaloid, quinine, anthraquinine whereas compounds as protein, saponin, starch, sterols and diterpenes were absent as summarized in Table 1. Plant extract having flavonoid, terpenoids, couramins are considered as a significant source of potential therapeutic compound for many ailment. Further the total flavonoid and phenolic compounds were quantified in the extract (Figure 1). The crude extract showed increased concentration of flavonoid and phenols with the

Table 1: Showing the phytoconstituents screened. + indicates the presence and - indicates absence of that phyto-constituent.

\begin{tabular}{|c|c|c|}
\hline S. No & Compounds & Present or Absent \\
\hline 1 & Tannins & + \\
\hline 2 & Phlobatanins & + \\
\hline 3 & Saponin & - \\
\hline 4 & Alkaloids & + \\
\hline 5 & Flavonoids & + \\
\hline 6 & Quinine & + \\
\hline 7 & Anthraquinones & + \\
\hline 8 & Coumarins & + \\
\hline 9 & Sterols & - \\
\hline 10 & Glycosides & + \\
\hline 11 & Terpenoids & + \\
\hline 12 & Diterpines & - \\
\hline 13 & Triterpenes & + \\
\hline 14 & Phenols & + \\
\hline 15 & Starch & - \\
\hline 16 & Carbohydrates & + \\
\hline 17 & Proteins & - \\
\hline
\end{tabular}




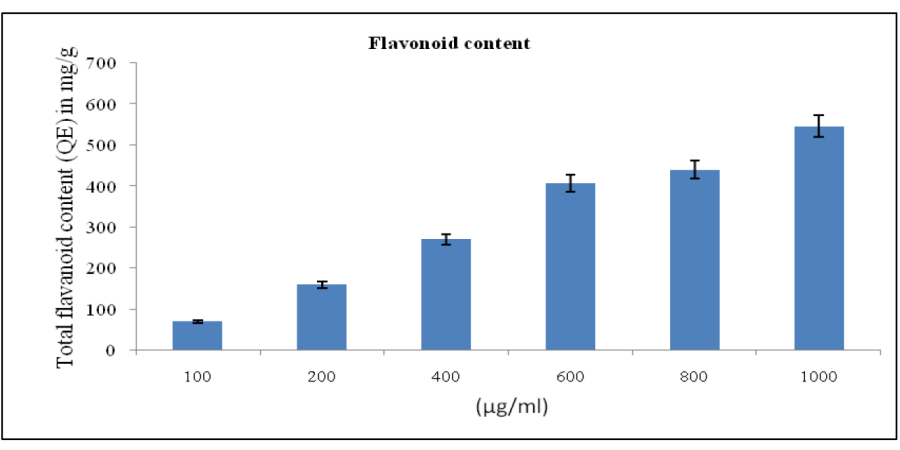

A

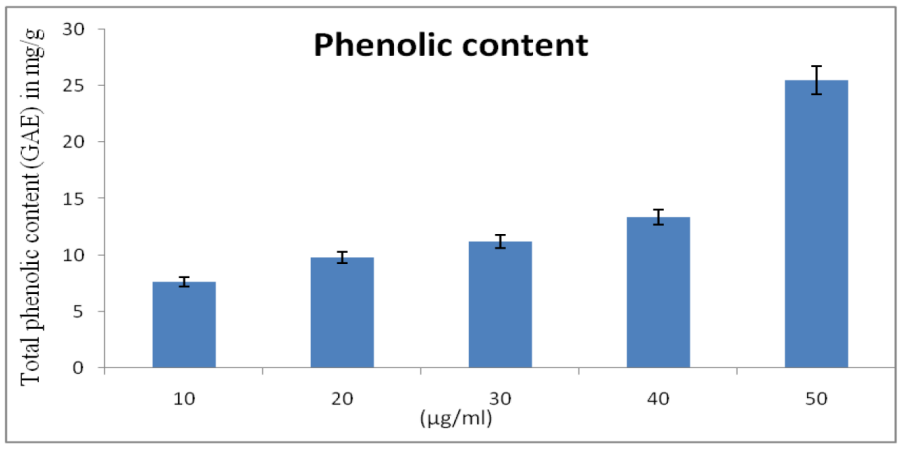

B

Figure 1: Showing the presence of total flavonoids $(A)$ and total phenolic content (B) in extract of Ocimum sanctum. increase concentration of $O$. sanctum. Both flavonoid and phenols due to its radical scavenging activity are considered to constitute the potent antioxidative property of herbal extract. ${ }^{[13]}$ Phenolic compound are supposed to exhibit significant free radical scavenging activity because of the presence of hydrogen or electron donating agent and metal ion chelating property. ${ }^{[14]}$ Similarly, flavanoids inhibit free radical mediated event by its chemical structure as these transfers electrons, chelate metal catalyst, activates antioxidant enzymes and inhibit oxidases. ${ }^{[14]}$ The result pertaining to GC-MS analysis of ethanolic extract of $O$. sanctum showed on a total of 40 identified compounds from the chromatogram as summarized in Table 2. The active principle (name), concentration (\% peak area) and retention time (RT) in the ethanol extract was identified for different compounds. The GC-MS spectrum confirmed the presence of various components with different retention times as illustrated in Figure 2. The identified compounds comprise mainly hydrocarbons, fatty acids, alcohols, esters and phenols. The composition of the extract comprises major component as Bicyclo[7.2.0]undec-4ene, 4,11,11-trimethyl-8-methylene- (24.22\%), Cyclohexane, 1-ethenyl1-methyl-2,4-bis(1-methylethenyl) (21.59\%), Oxatricyclo [8.2.0.0(4,6)] dodecane,12-trimethyl-9-methylene (7.27\%) and Eugenol (7.01\%). Among the identified phytocompounds, n-hexadecanoic acid, Octadecenoic acid and squalene (triterpine) have reported to exhibits the antioxidant, anti-inflammatory and antibacterial property. ${ }^{[15,16]}$ Eugenol, the main bioactive compound of $O$. sanctumhas been found to exhibit antimicrobial, anti-inflammatory and anti-oxidative, ${ }^{[17,18]}$ while coapene (a tricyclic serquiterpenes) has reported to act as anti-microbial and anti-oxidant property. ${ }^{[19,20]}$

Table 2: GC-MS spectral analysis of ethanolic extract of Ocimum sanctum.(Please See Supplementary file).

\begin{tabular}{|c|c|c|c|c|}
\hline Peak\# & R. Time & Area & Area\% & Name \\
\hline 1 & 7.843 & 141740 & 0.34 & BICYCLO[2.2.1]HEPTAN-2-OL, 1,7,7-TRIMETHYL-, (1S-ENDO)- \\
\hline 2 & 11.085 & 2952103 & 7.06 & Eugenol \\
\hline 3 & 11.343 & 231735 & .55 & Copaene \\
\hline 4 & 11.433 & 485878 & 1.16 & Cyclohexane, 1-ethenyl-1-methyl-2,4-bis(1-methylethenyl)-, [1S-(1.alpha.,2.beta.,4.beta.)]- \\
\hline 5 & 11.559 & 9027246 & 21.59 & Cyclohexane, 1-ethenyl-1-methyl-2,4-bis(1-methylethenyl)-, [1S-(1.alpha.,2.beta.,4.beta.)]- \\
\hline 6 & 12.082 & 10130388 & 24.22 & BICYCLO[7.2.0]UNDEC-4-ENE, 4,11,11-TRIMETHYL-8-METHYLENE-, [1R-(1R*4E,9S \\
\hline 7 & 12.657 & 601275 & 1.44 & 1,4,8-CYCLOUNDECATRIENE, 2,6,6,9-TETRAMETHYL-, (E,E,E)- \\
\hline 8 & 13.059 & 464226 & 1.11 & 1,6-CYCLODECADIENE, 1-METHYL-5-METHYLENE-8-(1-METHYLETHYL)-, [S-(E,E \\
\hline 9 & 13.194 & 363823 & .87 & Naphthalene, decahydro-4a-methyl-1-methylene-7-(1-methylethenyl)-, [4aR-(4a.alpha.,7.alph \\
\hline 10 & 13.302 & 470262 & 1.12 & ALPHA.-SELINENE \\
\hline 11 & 13.476 & 155084 & 0.37 & $\begin{array}{l}\text { CYCLOHEXANE, 1-ETHENYL-1-METHYL-2,4-BIS(1-METHYLETHENYL)-, [1S-(1.ALPHA.,2.BETA.,4. } \\
\text { BETA.)]- \$ } \$ \text { 2,4-DIISO, CYCLOPROP[E]AZULENE, Cycloheptane, 1,3,6,10-Cyclotetradecatetraene, }\end{array}$ \\
\hline 12 & 14.627 & 3039100 & 7.27 & (-)-5-OXATRICYCLO[8.2.0.0(4,6)]DODECANE,,12-TRIMETHYL-9-METHYLENE-, [1R \\
\hline 13 & 15.040 & 140599 & 0.34 & (1R,3E,7E,11R)-1,5,5,8-Tetramethyl-12-oxabicyclo[9.1.0]dodeca-3,7-diene \\
\hline 14 & 15.731 & 273776 & 0.65 & Isoaromadendrene epoxide \\
\hline 15 & 16.446 & 244474 & 0.58 & 2-((2R,4aR,8aS)-4a-Methyl-8-methylenedecahydronaphthalen-2-yl)prop-2-en-1-ol \\
\hline 16 & 16.698 & 737972 & 1.76 & 1,1,4,7-Tetramethyldecahydro- $1 \mathrm{H}$-cyclopropa[e]azulene-4,7-diol \\
\hline 17 & 18.010 & 224757 & 0.54 & Neophytadiene \\
\hline 18 & 19.717 & 1299736 & 3.11 & Ethyl 9-hexadecenoate \\
\hline 19 & 19.975 & 797570 & 1.91 & HEXADECANOIC ACID, ETHYL ESTER \\
\hline 20 & 20.317 & 149544 & 0.36 & 9-Hexadecenoic acid, (Z)-, TMS derivative \\
\hline 21 & 20.556 & 473909 & 1.13 & Palmitic Acid, TMS derivative \\
\hline
\end{tabular}

Continued... 


\begin{tabular}{|c|c|c|c|c|}
\hline \multicolumn{5}{|c|}{ Table 2: Cont'd } \\
\hline Peak\# & R. Time & Area & Area\% & Name \\
\hline 22 & 21.990 & 474438 & 1.13 & Ethyl Oleate \\
\hline 23 & 22.059 & 229917 & 0.55 & (E)-9-Octadecenoic acid ethyl ester \\
\hline 24 & 22.500 & 935411 & 2.24 & Phytol, acetate \\
\hline 25 & 23.205 & 245778 & 0.59 & Glycidyl oleate \\
\hline 26 & 23.419 & 229976 & 0.55 & Glycidyl palmitate \\
\hline 27 & 26.013 & 422106 & 1.01 & 1,2-BENZENEDICARBOXYLIC ACID \\
\hline 28 & 26.914 & 381217 & 0.91 & Eicosyl isopropyl ether, Hexadecyl isopropyl ether, Isopropyl tetradecyl ether \\
\hline 29 & 28.594 & 169550 & 0.41 & 2-methyloctacosane \\
\hline 30 & 30.587 & 619379 & 1.48 & Squalene \\
\hline 31 & 31.684 & 211876 & 0.51 & Hexatriacontane \\
\hline 32 & 32.902 & 259017 & 0.62 & Heptadecane, 3-methyl- \\
\hline 33 & 34.040 & 617018 & 1.48 & STIGMAST-5-EN-3-OL, OLEAT \\
\hline 34 & 34.314 & 422605 & 1.01 & Hexatriacontane \\
\hline 35 & 38.041 & 1804127 & 4.31 & Tetracontane \\
\hline 36 & 38.379 & 637256 & 1.52 & $\begin{array}{l}\text { Stigmast-5-ene, 3.beta.-(trimethylsiloxy)-, (24S)- \$\$ Silane, trimethyl[[(3.beta.,24S)-stigmast-5-en-3-yl]oxy]- } \\
\$ \$ \text { Silane, trimethyl(stigma }\end{array}$ \\
\hline 37 & 39.831 & 358191 & 0.86 & Dotriacontane, 1-iodo- \\
\hline 38 & 40.520 & 338846 & 0.81 & Tetrapentacontane \\
\hline 39 & 43.616 & 774787 & 1.85 & Hexatriacontane \\
\hline 40 & 45.303 & 283938 & 0.68 & Phytyl palmitate \\
\hline
\end{tabular}

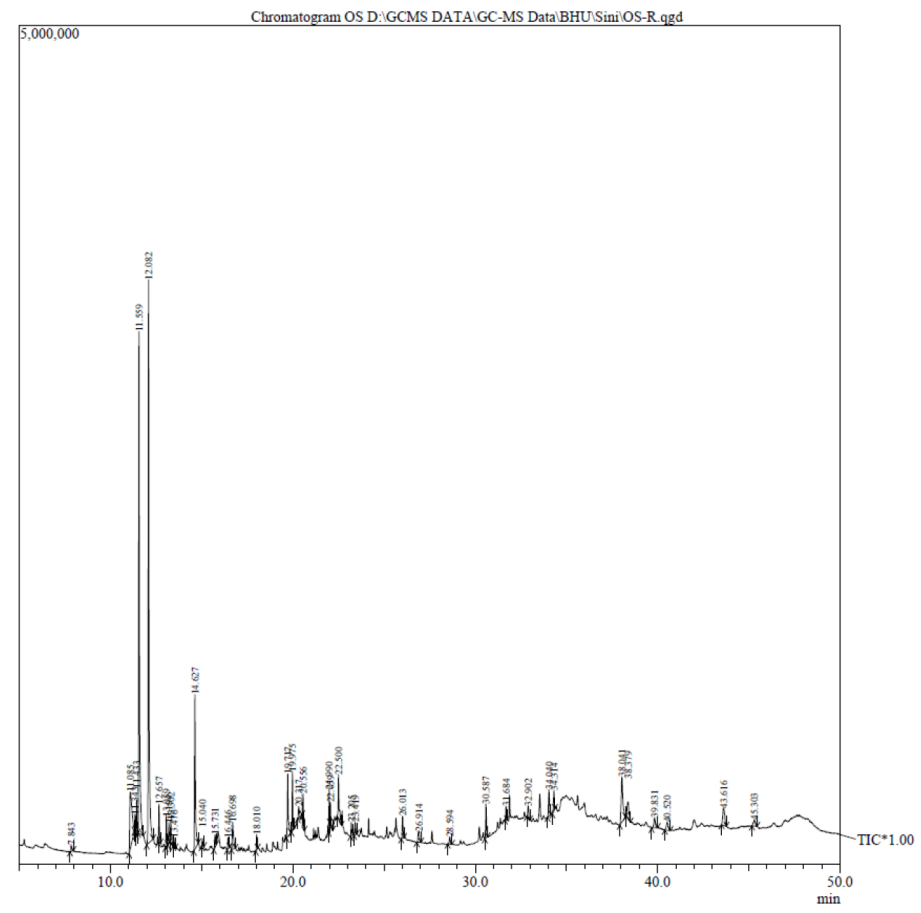

Figure 2: Showing the Chromatogram of Hydroethanolic leaf extract of Ocimum sanctum. (Please see supplementary file).
The presence of various bioactive compounds in the O. sanctum justifies the use of leaves extract for various ailments by traditional practitioners. However, isolation of individual phytochemical constituents and subjecting it to the biological activity will definitely give prolific results. The presence of various bioactive compounds makes O. sanctum applicable in various pharmaceutical and industrial applications and therefore it may be recommended as a plant of phytopharmaceutical importance.

\section{CONCLUSION}

The occurrence of various bio-active compounds detected in the GC-MS analysis using the ethanolic extracts of $O$. sanctum justifies the use of leaves of Tulsi plant for various elements by traditional practitioner. However, isolation of individual phytochemical constituents and analyzing its biological activity would be beneficial and would open a new area of investigation of individual compounds and their pharmacological potency. From these results, it could be concluded that "Ocimum sanctum" contains various bio-active compound which could provide therapeutic in several disorders. Hence further research is needed to explore its biological activity which is ongoing.

\section{ACKNOWLEDGEMENT}

The authors are highly thankful to All India research facility, Jawaharlal Nehru University, New Delhi to conduct the GC-MS analysis of the sample. 


\section{CONFLICT OF INTEREST}

The authors declared no potential conflicts of interest with respect to the research, authorship, and/or publication of this article.

\section{Financial Support}

The authors are highly thankful to Indian Council of Medical Research, New Delhi for providing funding in the form of Senior Research Fellowship to one of the author.

\section{ABBREVIATIONS}

GCMS: Gas chromatography and mass spectrometry; UV-VIS: Ultraviolet visible; RT: Retention Time; GAE: Gallic acid equivalent; QE: Quercetin equivalents; nm: nanometre; NIST14s.lib MS: National institute of standards and technology Mass spectroscopy library; WILEY8.LIB: Wiley online library.

\section{REFERENCES}

1. Yadav NP, Dixit VK. Recent approaches in herbal drug standardization. Int J Integr Biol. 2008;2(3):195-203.

2. Balandrin MF, Kinghorn $A D$, Farnsworth NR. Plant-derived natural products in drug discovery and development: an overview. ACS Symposium Series. 1993:2 12. doi: 10.1021/bk-1993-0534.ch001.

3. Pattanayak $P$, Behera $P, D a s ~ D, P a n d a ~ S K$. Ocimum sanctum Linn. A reservoir plant for therapeutic applications: an overview. Pharmacogn Rev. 2010;4(7):95-105. doi: 10.4103/0973-7847.65323, PMID 22228948.

4. Singh D, Chaudhuri PK. A review on phytochemical and pharmacological properties of Holy basil (Ocimum sanctum L.). Ind Crops Prod. 2018;118:367-82. doi: 10.1016/j.indcrop.2018.03.048.

5. Prakash P, Gupta N. Therapeutic uses of Ocimum sanctum Linn (Tulsi) with a note on eugenol and its pharmacological actions: a short review. Indian J Physiol Pharmacol. 2005;49(2):125-31. PMID 16170979.

6. Keshari AK, Srivastava A, Verma AK, Srivastava R. Free radicals scavenging and protein protective property of Ocimum sanctum (L). J Pharm Res Int. 2016;14(4):1-10. doi: 10.9734/BJPR/2016/31445.

7. Babu NR, Divakar J, Krishna UL, Vigneshwaran C. Study of antimicrobial, antioxidant, anti-inflammatory activities and phytochemical analysis of cooked and uncooked different spinach leaves. J Pharmacogn Phytochem. 2018;7(5):1798-803.

8. Jan S, Khan MR, RashidU, Bokhari J. Assessment of antioxidant potential, total phenolics and flavonoids of different solvent fractions of Monotheca buxifolia fruit. Osong Public Health Res Perspect. 2013;4(5):246-54. doi: 10.1016/j. phrp.2013.09.003, PMID 24298440.

9. Heinrich M. Ethnobotany and its role in drug development. Phytotherapy research: an international journal devoted to pharmacological and toxicological evaluation of natural product derivatives. Phytother Res. 2000;14(7):479-88. doi: 10.1002/1099-1573(200011)14:7<479::aid-ptr958>3.0.co;2-2, PMID 11054835.

10. Pushpangadan P, Bradu BL. Medicinal and aromatic plants. Adv Hortic. 1995; $11: 627-57$.

11. Politeo O, Jukic M, Milos M. Chemical composition and antioxidant capacity of free volatile aglycones from basil (Ocimum basilicum L.) compared with its essential oil. Food Chem. 2007;101(1):379-85. doi: 10.1016/j.foodchem.2006.01.045.

12. Pandey P, Grover K. Characterization of black carrot (Daucus carota L.) polyphenols; role in health promotion and disease prevention: an overview. J Pharmacogn Phytochem. 2020;9(5):2784-92. doi: 10.22271/phyto.2020.v9.i5am.12764.

13. Wangchuk P, Keller PA, Pyne SG, Taweechotipatr M, Kamchonwongpaisan S GC/GC-MS analysis, isolation and identification of bioactive essential oil components from the Bhutanese medicinal plant, Pleurospermum amabile. NatProdCommun. 2013;8(9):1305-8. doi: 10.1177/1934578X1300800930, PMID 24273872.

14. Chimi H, Cillard J, Cillard P, Rahmani M. Peroxyl and hydroxyl radical scavenging activity of some natural phenolic antioxidants. JAm Oil ChemSoc. 1991;68(5):307-12. doi: 10.1007/BF02657682.

15. GomathiD, Kalaiselvi M, Ravikumar G, Devaki K, Uma C. GC-MS analysis of bioactive compounds from the whole plant ethanolic extract of Evolvulusalsinoides (L.) L. JFoodSciTechnol. 2015;52(2):1212-7. doi: 10.1007/s13197-0131105-9, PMID 25694742.

16. Pu Z, Zhang Y, Yin Z, Xu J, Jia R, Lu Y, Yang F. Antibacterial activity of 9-octadecanoic acid-hexadecanoic acid-tetrahydrofuran-3,4-diyl ester from neem oil. AgricSciChina. 2010;9(8):1236-40. doi: 10.1016/S1671-2927(09)60212-1.

17. Asha MK, Prashanth D, Murali B, PadmajaR, Amit A. Anthelmintic activity of essential oil of Ocimum sanctum and eugenol. Fitoterapia. 2001;72(6):669-70 doi: 10.1016/s0367-326x(01)00270-2, PMID 11543966.

18. Gülçin I. Antioxidant activity of eugenol: A structure-activity relationship study. JMedFood. 2011;14(9):975-85. doi: 10.1089/jmf.2010.0197, PMID 21554120.

19. Türkez H, Celik K, Togar B. Effects of copaene, a tricyclic sesquiterpene, on human lymphocytes cells in vitro. Cytotechnology. 2014;66(4):597-603. doi: 10.1007/s10616-013-9611-1, PMID 24287609.

20. Kuang-Ping H, San-Hsien T, Yu-Chang $S$, Chen-Lung $H$. Chemical composition and antimicrobial activity against food borne pathogens of Calocedrus formosana heartwood essential oil. NatProdCommun. 2021;16(5):1-8.

\section{GRAPHICAL ABSTRACT}

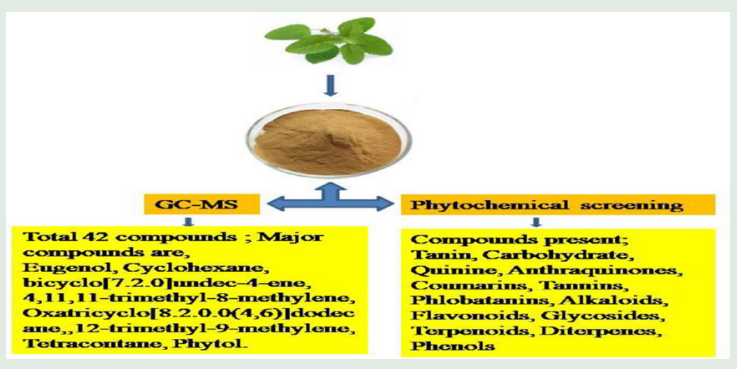

\section{SUMMARY}

The results obtained from phytochemical screening studies identified the presence of tannins, carbohydrate, quinine, anthraquinones, coumarins, phlobatanins, alkaloids, flavonoids, glycosides, terpenoids, diterpenes and phenols. In GC-MS analysis; 40 different compounds with 7 major components Eugenol, Cyclohexane, bicyclo[7.2.0]undec-4-ene, 4,11,11-trimethyl-8-methylene, Oxatricyclo[8.2.0.0(4,6)]dodecane,,12trimethyl-9-methyleneTetra contane, Phytol were found. These compounds possess important biological activity and strongly support the pharmacological potency of Ocimum.

Cite this article: Srivastava A, Subhashini, Keshari AK, Srivastava R. Phytochemical and GC-MS Analysis of Hydro Ethanolic Leaf Extract of Ocimum sanctum (L). Pharmacog Res. 2021;13(4):233-7. 